\section{A CONVERSATION WITH}

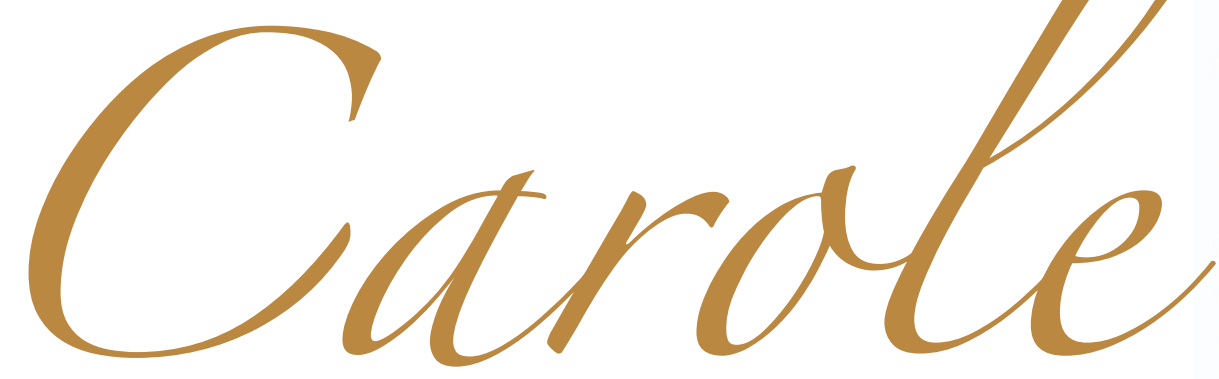

\section{Carole Haynes* quit cadet general nursing at 17} as she just wanted to have fun... but these days she is an advocate for dental nurses specialising in special care.

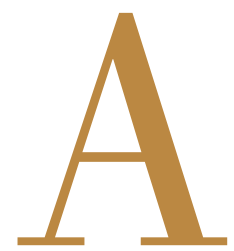

\author{
fter leaving school I had \\ intended to become a \\ general nurse working in \\ a hospital on the wards, \\ but after applying for \\ cadet nursing, and getting
} accepted onto a course, I then declined to take up the role as I realised that I would be expected to work weekends. I was only 17 and wanted my weekends free to go out with my friends to have fun.

Dental nursing was an afterthought; it offered 9-5 hours of work with weekends off. I was also wearing a nurse uniform and carrying out nurse duties: it suited me.

My first job in dentistry was in a high street general dental practice. I was given six weeks to learn all I could as the dental nurse who was showing me what to do was going on maternity leave. I was amazed at how quickly I learnt; the boss was very pleased with my work.

I enjoyed the whole patient care part of the job. Many patients found the dental experience quite fearful. I enjoyed reassuring the patients and supporting them through the treatment. I liked to think that my contribution to the patient's treatment was of great value.

After qualifying as a dental nurse I decided to take a job in Libya, North Africa where

\footnotetext{
* Carole Haynes is a qualified dental nurse with Certificates in Oral Health Education and Special Care Dental Nursing, an NVQ Level 3 in Health \& Social Care (Adults), the Al Assessors Award in Dental Nursing, Certificate in Management and a C\&G Licentiateship in Dental Nursing. Carole is past Chair of BADN's Special Care \& Sedation National Groups, past Trustee of the $B D H F$ and a member of the British Society for Disability and Oral Health.
}

I worked as a senior dental nurse, training the Libyan nurses and showing them how to maintain the dental equipment.

After completing my contract of one year, I returned to London and took a job in another high street dental practice. During my time there I worked as the head dental nurse over four surgeries.

After that I worked for Camberwell Community Dental Service. My role was assisting within the dental clinics throughout the South London boroughs of Lambeth, Southwark and Lewisham. I became qualified in oral health education and then followed on with the City \& Guilds A1 Assessor award.

I have always held the view that dental nursing is, for dental nurses, the foundation to build upon and you should look at ways you could enhance the patient experience. This can only happen by becoming better qualified and experienced in your own delivery of dental care within the dental team.

I trained as a dental nurse assessor at Guy's Dental Hospital. I had the desire to pass on my skills to trainee dental nurses; it's important to keep standards at the best possible level to benefit the patients. I wanted to be involved in achieving and maintaining standards.

I first became interested and involved in special care dentistry when I worked in the psychiatric hospital in Tooting Bec, where I accompanied the dental officer on the open wards and the locked wards. I enjoyed my years working there and was especially interested in all the new studies that went on. Whenever research was being carried out about the patients, the dentist and I would take part in it by collecting any relevant data required. I would ask for and analyse the data when the research was completed. All of that knowledge just stretched my mind..

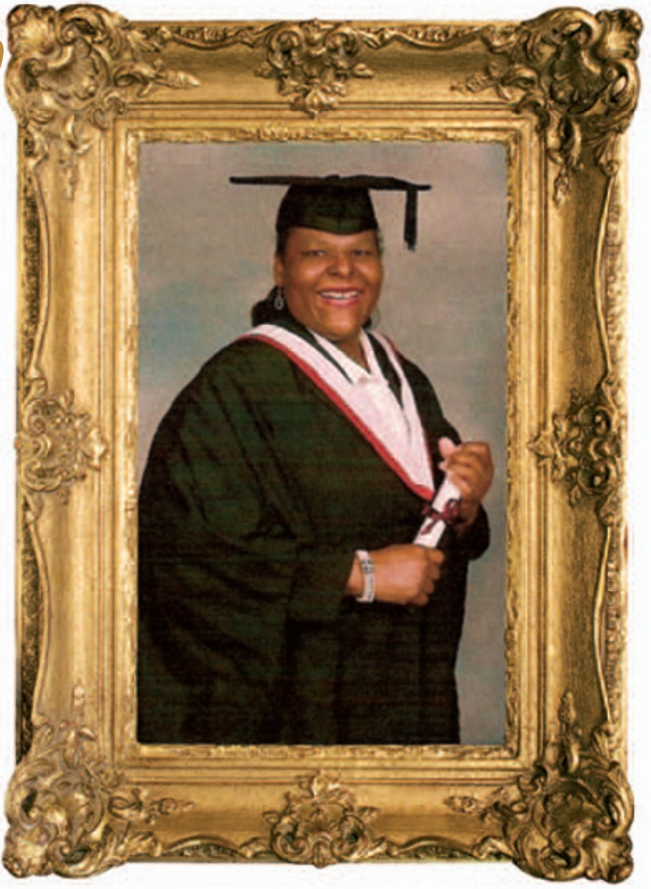

Patients that require special care dentistry require a dedicated team of professionals to carry out their dental care.

As most are aware, special care dentistry has now become a specialty with the specialist dentist names placed on a list with the GDC.

I am interested in dental nurses in special care dentistry also becoming recognised as specialists after gaining the Certificate in Special Care Dental Nursing and showing evidence of their experience. I am working on it...

In my area and other areas in and around the UK, provision for patients in need of special care dentistry is uneven. In some areas special care patients are able to access dental care whilst in other areas access is not so readily available.

At present I am a carer to my father who has suffered a stroke and to my son who is now in college and requires assistance with travelling to and from college.

I attend college part-time studying for the Certificate in Teaching in the Lifelong Learning Sector. I am developing my skills and knowledge so that I can then teach qualified dental nurses in different subjects and who work in different environments, in relation to special care dentistry.

My studies are a follow on from the Preparing to Teach in the Lifelong Learning Sector course. There is so much dental nurses can learn and many more skills to acquire within the special care settings. I am really looking forward to writing and delivering lesson plans.

I am passionate about the future for dental nurses who are working in special care and I am looking forward to being involved in their development ... watch this space. 